\title{
The Role of Grammar Awareness in Learning English Wh-Movement by Chinese L2 Learners
}

\author{
Kun Hou ${ }^{1} \&$ Sanooch Segkhoonthod Na-Thalang ${ }^{2}$ \\ ${ }^{1}$ Suranaree University of Technology, Nakhon Ratchasima, Thailand \\ ${ }^{2}$ Suranaree University of Technology, Nakhon Ratchasima, Thailand \\ Correspondence: Kun Hou, English Department, School of Foreign Languages, Suranaree University of \\ Technology, Nakhon Ratchasima, Thailand. Tel: 66-803-323-297; 86-135-9506-7744. E-mail: \\ kunhou060611@gmail.com
}

Received: June 6, 2013 Accepted: July 4, 2013 Online Published: August 15, 2013

doi:10.5539/ells.v3n3p56 URL: http://dx.doi.org/10.5539/ells.v3n3p56

\begin{abstract}
This experimental study aimed at examining the role of grammar awareness in learning English wh-movement by Chinese EFL learners. Eighty adult native speakers of Chinese took grammaticality judgment tests (GJT) in order to find out whether they were constrained by Chinese wh-in-situ parameters. The mean scores of the GJT in the pretest and posttest were compared to observe the effect of the grammar awareness-raising model (GARM) guided instruction on wh-movement. Both within-group and between-group comparisons showed that when L2 learners were aware of the target linguistic phenomenon, their performance in judging the grammaticality of the wh-movement was improved. It is concluded that the role of grammar awareness in learning English wh-movement is positively related to the subjects' performance in GJT.
\end{abstract}

Keywords: universal grammar, wh-movement, second language acquisition, grammar awareness, L2 parameters resetting

\section{Introduction}

\subsection{Background to the Study}

Since the second half of the last century, Chomsky's universal grammar (UG) has been one of the most heatedly debated theories due to its creative explanation of first language acquisition. Research on SLA has witnessed numerous revolutions since then. One of them is the shift of viewing how a second language is acquired from external factors to internal factors under the UG paradigm proposed by Chomsky (1975). According to Chomsky (1986), first language (L1) acquisition device is something innate as a genetic faculty. People learn their first language as they biologically and naturally grow up.

However, L2 learning was more sophisticated comparing to L1 acquisition. While a learner was learning an L2, he/she needed to pay laborious efforts in understanding how to operate the target linguistic structure. Therefore, the role of awareness in L2 learning became the focus of the present study. Among all the principles and parameters defined by Chomskyan researchers since 1960's, the wh-movement has been studied for its different characteristics in wh-components moving languages and wh-component non-moving languages. English is a wh-movement language whereas Chinese is well known for its wh-in-situ parameter.

Up to now, there have been many studies on the acquisition of wh-movement by L2 learners of English from different language backgrounds, e.g. Choi (2007), Tsimpli and Dimitrakopoulou (2007), Park (2000), Bley-Vroman and Yoshinaga (2000) and White and Juffs (1998), or how English speaking L2 learners of Chinese produce Chinese wh-questions. However, this present study will focus on what problems Chinese speaking learners of English have while they are learning English wh-movement.

\subsection{Statement of the Problem}

This present study is concerned with characterizing and categorizing the problems that Chinese university EFL learners encounter while they are learning English wh-movement. It is observed that Chinese-speaking learners of English make ungrammatical sentences as

$1 \mathrm{a}{ }^{*}$ To whom did the teacher teach them knowledge and morality? (Note 1) 
(To whom did the teacher teach knowledge and morality?)

$1 \mathrm{~b}$ *John told his wife when would he arrive at the office.

(John told his wife when he would arrive at the office.)

$1 \mathrm{c}$ *Why Sudan is so poor?

(Why is Sudan so poor?)

The phenomenon under investigation is English direct and indirect wh-questions made by Chinese learners of English. Experimental data of the grammaticality judgment test (GJT) were collected for the purpose of observing L2 learners' performance on wh-movement. The researcher coded and categorized the grammar errors made by L2 learners. This study mainly aims at examining the problems in learning English wh-movement by Chinese learners of English and the role of language awareness in L2 grammar learning process.

As we might observe, L1 acquisition requires no special attention to the language rules whereas adult learners of a second language do not own that L1 ability. L2 learners' awareness of certain linguistic phenomenon needs to be highlighted or triggered with external methods, such as practicing or memorizing, as N. C. Ellis (2002, p. 299) claims that SLA theory and neuroscience of learning and memory are closely connected. The role of consciousness in learning L2 should not be neglected and it is most thoroughly discussed in Schmidt's Noticing Hypothesis (Schmidt, 1990). This study focused on the role of the grammar awareness in English wh-movement acquisition by Chinese L2 learners of English.

\subsection{Relevant Literature}

The role of language awareness in SLA has been discussed by scholars such as Al-Hejin (2005); Kennedy (2012); Rezaei and Hosseinpur (2011); Schmidt (2012); Svalberg (2007). They believed that the language awareness functions as the trigger of noticing the target linguistic structure.

As what was suggested by Allport (1988), there were three prerequisites for a person to be aware of a given experience. Firstly, there should be cognitive change as the result of the experience. Secondly, a learner needs to report the awareness of the experience when it happens. And thirdly, a learner should be able to describe the experience.

Reber (1989, p. 219) argued that implicit learning referred to "the process by which knowledge about the rule governed complexities of the stimulus environment is acquired independently of conscious attempts to do so". Moreover, explicit learning happened when the learner is aware of and actively involved in the processing of the input.

Schmidt's Noticing Hypothesis (1990) was the millstone of the theories concerning the language awareness. Schmidt (1990) argued that subconscious language learning was impossible. Noticing was the necessary and sufficient condition for L2 learners to convert input to intake. Moreover, paying attention was facilitative and necessary for adult learners to acquire grammatical features.

Shahrour and Bull (2008) investigated the potential for prompting noticing in language learning using an open learner model (OLM) and the conclusion was that an awareness-raising technique used in an OLM may help language learners to notice target forms. The learners may be able to internalize correct forms into their language system, using an OLM such as Notice.

Nazari (2013) investigated how implicit and explicit methods of instruction might affect the learners' achievement in both receptive and productive modes. It was concluded that when the participants focused more on the content, they were less likely to learn specific grammar structures. Explicit teaching strategy was more effective than the implicit one. When learners were informed of the grammatical rules, they felt more comfortable, self-confident and motivated in the classroom.

This present study studied the role of awareness in learning English wh-movement. Up to date, studies about the wh-movement acquisition by learners of English have been carried out since the end of last century such as Li (1998), White and Juffs (1998), Hawkins and Hattori (2006), Slavkov (2009) and Tayyebi (2012). These researches concentrated on the influences of the native languages on the acquisition of the wh-movement whereas did not take the L2 learners language awareness into consideration. Therefore, the present study explored the role of language awareness, specifically narrowed down to grammar awareness, in learning English wh-movement.

\subsection{Research Hypothesis and Questions}

It is hypothesized that L2 learners' grammar errors concerning the movements of wh-components as well as 
auxiliary verbs or tense indicators and wh-movement constraints may be abated if they become aware of how and why English wh-components are moved back and forth.

Based on the research hypothesis, the following research question was therefore proposed.

1. Are there any differences among Chinese L2 learners in detecting wh-movement errors before and after grammar awareness-raising model (GARM) based explanations on wh-movement? If yes, what are they?

2. What are the grammatical errors made by L2 English learners concerning wh-movement?

\section{Methodology}

\subsection{Participants}

The participants of this study were eighty first-year English majors, coming from four classes enrolled in Guizhou University, China in the year 2011. Two classes, totaling 40 students, made the treatment group (TG) which received instruction on wh-movement. Another two natural classes, totaling 40 students made the non-treat group (NTG) which received the same amount of linguistic materials as TG from the researcher, but without instructions on wh-movement because this research aimed at observing the effect of special treatment to Chinese EFL learners. All participants were intermediate-leveled learners of English. The control group (CG) consisted of 10 native speakers.

\subsection{Research Instruments}

The adopted research instrument was grammaticality judgment test (GJT). The GJT consisted of 20 ungrammatical and 10 grammatical sentences. The ungrammatical sentences were 2 subject wh-questions, 2 object wh-questions, 6 adjunct wh-questions, 2 embedded subject wh-questions, 2 embedded object wh-questions and 6 embedded adverb wh-questions, with 10 grammatical ones, one for each type as control sentences. The ungrammatical ones involved ungrammatical fronting of auxiliary verb in these sentences repectively. The control sentences had the same structures with the ungrammatical ones but with different contents. The sentence types are illustrated in Table 1.

Table 1. Question types in GJT

\begin{tabular}{lll}
\hline Question types & Question subtypes & Sample ungrammatical questions \\
\hline Direct questions & Subject & "Who did watched a movie? \\
& Adjunct & "What Eileen wrote in the letter? \\
& & ${ }^{*}$ Why Africa is so poor? \\
& & \\
& *Where she put the birthday cake? \\
(embedded) & Subject & ${ }^{*}$ Could you tell me did who give that book to you? \\
questions & Object & ${ }^{*}$ Can you tell me what is your name? \\
& Adjunct & ${ }^{*}$ The doctor told me why was he so sick. \\
& & ${ }^{*}$ Eileen sent a letter telling me when would she arrive at Beijing. \\
& & Eileen argued with us where should we hold the ceremony. \\
\hline
\end{tabular}

Description: Table 1 displayed the question types appeared in the GJT pretest and posttest.

There were two ungrammatical ones and one grammatical one of each subtype. The purpose of the ungrammatical sentences was to test whether the participants were able to detect violations of wh-movement. The grammatical questions were designed as control sentences in order to find out whether wh-movement parameters were set in the Chinese participants' minds. The grammatical and ungrammatical sentences were presented to the participants in random order for the purpose of investigating whether Chinese L2 English were able to distinguish questions that violated wh-movement from grammatical wh-questions as the native speakers did. 


\subsection{Research Procedures}

\subsubsection{Pretest}

In this phase, all of the participants participated in GJT. After the task was done, the scores were compared and analyzed statistically, using t-test. And the types of errors made by the participants were counted.

In the GJT, the non-native speakers (NNS) subjects, i.e. TG and NTG needed to judge whether the sentences were grammatical or not, and then made necessary corrections to what was believed to be ungrammatical.

The scoring standard of GJT is shown as follows,

$\begin{array}{ll}\text { Judge "yes" to grammatical interrogative question (IQ) } & 2 \mathrm{pt} \\ \text { Judge "no" to ungrammatical IQ } & 1 \mathrm{pt} \\ \text { Judge "yes" to ungrammatical IQ } & 0 \mathrm{pt} \\ \text { Judge "no" to grammatical IQ } & 0 \mathrm{pt} \\ \text { Correctly make corrections to ungrammatical IQ } & 1 \mathrm{pt} \\ \text { Make unnecessary corrections to the grammatical sentence } & 0 \mathrm{pt}\end{array}$

Since this research concerned the wh-movement, any grammatical mistakes other than wh-movement such as tense and aspect were not counted.

\subsubsection{Instruction on Wh-Movement}

In this phase, the researcher was the instructor explaining wh-movement parameters in English to the participants.

During every session of wh-movement, the participants watched ten plots taken from an English movie about campus life containing the target linguistic phenomenon. After watching the plots, the participants were required to figure out the target structures in these plots.

Then the researcher delivered instruction on the wh-movement explaining how the wh-words, and the auxiliary verb, were fronted to the beginning in order to transform a declarative sentence into a wh-question in English.

After explaining the movement of wh-component, the participants understood that the wh-component in an English interrogative sentence was moved from its original place in 2a to the beginning of the direct question, and left a trace behind indicated by an italicized t. $2 \mathrm{~b}$ as shown below.

2a. That was exactly what. (Chinese wh-question wording)

2b. What $t_{\mathrm{t}}$ exactly was that $\mathrm{t}$ ? (English wh-question wording)

What makes the GARM based instruction different from what the NTG subjects received, and the reasons for providing the participants with plots containing English wh-questions taken from English movies are as follows. First, the content in which a conversation happens helps the participants understand how native speakers ask for information using wh-questions. This audio-visual method is different from reading written forms, such as textbooks and articles in raising learners' awareness to target language grammar, because to directly watch how things going on visually may highlight L2 learners' impression on how a language is used in real life (Alanen, 1995). Second, this GARM encourages L2 learners to observe how language is used between native speakers in real life before the learners start to produce their own sentences. Although what has been done by the other grammar teachers is also to provide grammatical L2 sentences, this teaching model values more on making L2 learners notice the target language phenomenon in real situation by listening and seeing. Thirdly, audio-visual method is adopted in this research for the purpose of raising L2 learners' awareness, which is different from traditional English grammar course that prescibes L2 learners what should be done in order to make grammatical sentences. However, the present GARM guides learners to first observe L2 sentences in real situation and then provides explanations on why English wh-questions are produced this way instead of Chinese wh-question wording. In other words, GARM emphasizes the meta-linguistic method in teaching L2 grammar.

After watching all the English scenes, the participants of this study received an article containing target linguistic phenomenon. Sentences containing wh-questions were required to be underlined by the participants for the purpose of reminding them how grammatical L2 wh-questions were formed. The learners were reminded to notice the wh-questions in the article, and reviewed how an English wh-question was made by fronting the wh-component and auxiliary verb, including tense indicator -es or -ed. When the participants noticed the underlined wh-questions, they were asked to make sentences following the underlined questions. And at the same time, the researcher provided corrective feedback to the participants once there appeared ungrammatical 
sentences.

After receiving instructions on wh-movement, the participants needed to finish after-school assignments. The assignment required the participants to find out wh-questions sentences according to what they learned during that session from materials written in English and to make corresponding sentences according to the syntactic structure of the identified English sentences. The participants needed to hand in their assignment before they took part in next session on wh-movement. Moreover, their assignment was graded by the researcher and corrective feedbacks were returned to the participants.

\subsubsection{Posttest}

During this phase, all the participants in the TG NTG and CG took a GJT again for the purpose of observing whether there were any differences of making wh-question after receiving instructions on wh-movement. The papers were evaluated by the researcher based on the same standard in the pretest. The results of the two tasks were analyzed statistically using t-test to compare both among groups and between tests.

\section{Results}

In response to the first research question, “Are there any differences among Chinese second language learners in detecting wh-movement errors before and after the instruction based on the GARM?" the analysis of the results of the GJT were considered as results to the question.

\subsection{Quantitative Data}

\subsubsection{A Comparison of the Pretest among Groups}

The results indicated that the TG and NTG performed significantly different from the CG in the pretest respectively $(t=4.079, p=0.00<0.05$ for the $T G ; t=5.100, p=0.00<0.05$ for the NTG). However, There was no significant difference between the TG and NTG in the pretest $(t=0.672, p=0.503>0.05)$, which meant that both non-native speaker groups, i.e. TG and NTG, performed similarly in the pretest.

\subsubsection{A Comparison of the Posttest among Groups}

The comparison of the posttest mean scores in GJT of each group was conducted to determine whether there were any changes to the subjects after the GARM based instruction on wh-movement. Independent samples t-test was adopted to compare the TG with the NTG in order to find out if the former performed significantly different from the latter in the posttest. At the same time, the results of the two non-native speaker groups were also compared with those of the CG to observe the extent to which the non-native speakers were different from the native speaker subjects.

The scores of the three groups in the posttest showed that TG performed differently from the CG ( $\mathrm{t}=4.686$, $\mathrm{p}=0.000<0.05$ ), which meant that this group of subjects, who were L2 English learners, performed statistically different from the native speakers. Moreover, there was also no significant difference between the NTG and the CG $(t=7.48, p=0.000<0.05)$, which indicated that the NTG subjects did not perform significantly different from the CG subjects. Meanwhile, the means of the TG was statistically different from that of the NTG ( $\mathrm{t}=4.389$, $\mathrm{p}=0.000<0.05$ ), which seemed to indicate that the TG improved their performance in making judgment on the grammaticality of the wh-moment, whereas the subjects of the NTG remained steady.

\subsubsection{A Comparison of the Pretest and Posttest within Groups}

According to the raw data collected from the GJT, for the purpose of finding out whether the GARM took effect in the instruction, the mean scores of the pretest and posttest were compared using paired samples t-test.

The TG exhibited significant difference between pretest and posttest $(\mathrm{t}=2.55$, sig. $=0.015<0.05)$, whereas the results of the NTG showed no significant difference $(t=1.77$, sig. $=0.085>0.05)$. The subjects in the TG achieved better results in the posttest than in the pretest. Therefore, it could be inferred that the GARM helped the subjects understand how to move the wh-component, as well as INFL within a sentence in order to make an English wh-question. There was no significant difference in the CG because the native speakers' language level remained still in the pretest and posttest.

\subsection{Qualitative Data}

In response to the research question, "What are the grammatical errors made by L2 English learners concerning wh-movement before and after GARM based explanations on wh-movement?” the major types of movement errors were counted and compared quantitatively and qualitatively so as to reflect the influence of the instruction of wh-movement based on GARM.

According to the test papers done by the subjects, the errors in the GJT may be generalized and categorized as 
follows.

Table 2. Types of errors in GJT

\begin{tabular}{|c|c|c|c|}
\hline No. & Types of errors & Meaning & Examples \& explanations \\
\hline 1 & No movement & $\begin{array}{l}\text { The subjects made } \\
\text { incorrect judgment to } \\
\text { grammatical } \\
\text { wh-questions but made } \\
\text { no correction to them. }\end{array}$ & $\begin{array}{l}\text { The subject judged the grammatical sentences as } \\
\text { ungrammatical but didn't make any correction to it. }\end{array}$ \\
\hline 2 & $\begin{array}{l}\text { Double tense } \\
\text { indicator }\end{array}$ & $\begin{array}{l}\text { The subjects didn't } \\
\text { notice there was more } \\
\text { than one auxiliary verb } \\
\text { or INFL. }\end{array}$ & $\begin{array}{l}\text { *Please tell me who did sent him an email to explain the } \\
\text { situation. }(\sqrt{ }) \\
\text { The subject judged the ungrammatical sentence as } \\
\text { grammatical and made no correction because he didn't } \\
\text { know that the words "did" and "sent" involved two } \\
\text { INFL-past tense indicators which should not coexist. } \\
\text { This sentence should be marked with " } \times \text { " and corrected } \\
\text { into "Please tell me who sent him an email to explain the } \\
\text { situation". }\end{array}$ \\
\hline 3 & $\begin{array}{l}\text { No movement } \\
\text { forward }\end{array}$ & $\begin{array}{l}\text { The subjects didn't front } \\
\text { the auxiliary or the tense } \\
\text { indicator to form a direct } \\
\text { wh-question. }\end{array}$ & $\begin{array}{l}\text { *To whom John gave a glass of water? }(\sqrt{ }) \\
\text { The subject believed that this wh-question was correct. } \\
\text { But actually he needed to front the INFL-past to be after } \\
\text { the wh-word. This sentence should be marked with " } \times \text { " } \\
\text { and corrected into "To whom did John give a glass of } \\
\text { water?" }\end{array}$ \\
\hline 4 & $\begin{array}{l}\text { No movement } \\
\text { backward }\end{array}$ & $\begin{array}{l}\text { The subjects didn't move } \\
\text { the auxiliary or the tense } \\
\text { indicator while making. }\end{array}$ & $\begin{array}{l}\text { *Could you tell me which bus should I take to get to the } \\
\text { hospital? }(\sqrt{ }) \\
\text { The subject judged the ungrammatical sentence as } \\
\text { grammatical and made no correction to it. } \\
\text { But the auxiliary verb "should" was incorrectly fronted } \\
\text { and should be moved back to be after the subject of the } \\
\text { relative clause as, "Could you tell me which bus I should } \\
\text { take to get to the hospital?" }\end{array}$ \\
\hline 5 & $\begin{array}{l}\text { Over } \\
\text { generalization }\end{array}$ & $\begin{array}{l}\text { The subjects front some } \\
\text { parts that should not be } \\
\text { fronted. }\end{array}$ & $\begin{array}{l}\text { Who on earth made a promise to Eileen? }(\times) \rightarrow \text { Who } \\
\text { made a promise on earth to Eileen? } \\
\text { The subject judge a grammatical wh-question as } \\
\text { ungrammatical and made unnecessary movement to the } \\
\text { phrase "on earth". }\end{array}$ \\
\hline 6 & $\begin{array}{l}\text { Other } \\
\text { errors }\end{array}$ & $\begin{array}{l}\text { The subjects made errors } \\
\text { such as deletion, adding } \\
\text { unnecessary word or } \\
\text { making unnecessary } \\
\text { corrections. }\end{array}$ & $\begin{array}{l}\text { David proposed to the committee when they would be } \\
\text { able to finish the project. }(\times) \rightarrow \text { David proposed to go to } \\
\text { the committee when they would be able to finish the } \\
\text { projects. } \\
\text { The subject judged the grammatical sentence as } \\
\text { ungrammatical and added unnecessary information to the } \\
\text { sentence. The indirect wh-question was thus changed into } \\
\text { an adjunct clause. }\end{array}$ \\
\hline
\end{tabular}

Description: Table 2 displays the types of errors made by the subjects in GJT. It included the description of each error and examples were also provided. 


\subsubsection{Frequency of GJT Errors in Pretest}

For the purpose of observing the differences of the grammar errors in the pretest and posttest, the frequencies of the grammar errors made by the subjects of the TG and NTG were compared, and the results may be shown in Table 3.

Table 3. Frequency of grammar errors in GJT pretest

\begin{tabular}{llllllll}
\hline & 1 & 2 & 3 & 4 & 5 & 6 & $\mathrm{~N}=$ \\
\hline TG & 26 & 33 & 148 & 140 & 33 & 50 & 430 \\
NTG & 27 & 35 & 156 & 171 & 35 & 51 & 475 \\
\hline
\end{tabular}

Description: Table 3 presented the number of each type of errors made by the subjects in the TG and NTG in GJT pretest.

According to the data in Table 3, the third and fourth errors appeared much often in the non-native speaker groups. Comparatively speaking, the subjects in the TG achieved more correct items than those in the NTG. The NTG made more errors in moving the auxiliary verb forwards and backwards in the direct and indirect wh-questions. Pearson chi-square was used to compare the relationship between the frequencies of the grammar errors of the two groups in the pretest. It was reported that there was significant relationship between the TG and NTG in the pretest $(\mathrm{P}=4.8$, sig. $=0.57>0.01)$, which indicated that the TG and NTG made close numbers of errors.

\subsubsection{Frequency of GJT Errors in Posttest}

In order to find out whether the instruction on the wh-movement had any influence on the subjects to move the auxiliary verbs or tense indicators while making direct and indirect wh-questions, the frequency of the errors in the posttest were analyzed and the results may be illustrated in the following table.

Table 4. Frequency of grammar errors in GJT posttest

\begin{tabular}{llllllll}
\hline & 1 & 2 & 3 & 4 & 5 & 6 & $\mathrm{~N}=$ \\
\hline TG & 22 & 36 & 159 & 106 & 6 & 59 & 388 \\
NTG & 36 & 69 & 220 & 252 & 7 & 64 & 648 \\
\hline
\end{tabular}

Description: Table 4 presented the number of each type of errors made by the subjects in the TG and NTG in GJT posttest.

According to Table 4, the subjects of the TG made more correct judgment than those of the NTG. Comparing to the NTG, the TG subjects achieved more successfully while making judgment on the movement of the auxiliary verb or INFL in a direct or indirect wh-question. Pearson chi-square was used to compare the relationship between the frequencies of the grammar errors of the two groups in the posttest and the result showed that there was no correlation between the frequencies $(\mathrm{P}=132.9$, sig. $=0.00<0.01)$.

\section{Discussion}

\subsection{Research Question 1}

In response to the first research question "Are there any differences among Chinese L2 learners in detecting wh-movement errors before and after grammar awareness-raising model (GARM) based explanations on wh-movement”, the GJT mean scores of each group in the pretest and posttest were compared. The results of the comparison will be discussed in the following three parts.

\subsubsection{A Comparison of the Pretest among Groups}

In the pretest, both the treatment group (TG) and non-treatment group (NTG) performed significantly different from the native speaker group, namely control group (CG), and the two groups of non-native speakers had similar results in the pretest. This may be interpreted that in the pretest, the subjects of the TG and NTG had almost the same level in judging the grammaticality of the wh-questions. They maintained low accuracy in making proper judgment to those items with improper auxiliary verb movements compared to that of the native speakers. The subjects' judgment exhibited characteristics of Chinese wording order. Take item 4 in the pretest as 
an example numbered here as 3 .
3. *Why
Africa
is so poor?
Weishenme feizhou shi ruci pinqiong?

15 and 20 out of 40 in the TG and NTG respectively judged this wh-question grammatical. The reason was that the English wh-question followed the same order as the corresponding Chinese question. Therefore, the subjects were under the influence of their L1 and their L2 output exhibited Chinese wh-question orders. $62.5 \%$ of the subjects from the TG and 50\% of the subjects from the NTG did not notice that the auxiliary verb should be after the wh-word "why". On the contrary, the native speakers judged this wh-question ungrammatical because the verb "is" should be replaced to be after the wh-word "why".

\subsubsection{A Comparison of the Posttest among Groups}

Statistically significant changes happened among the TG, the NTG and the CG in the posttest after the instruction. After the TG received the instructions on the wh-movement, the mean score of the TG was highly improved and they performed significantly different from those in the NTG, which means that the NTG remained unchanged compared to their performance on the pretest. However, there were also statistically differences between the TG and the CG. The reasons of this may be explained from two aspects.

The first aspect is concerned with the input that the subjects receive. The NTG received the same L2 materials as the TG did. The researcher helped them understand the general meaning of the passages, and they could read them without any pressure of time limit or vocabulary. Meanwhile, the researcher avoided emphasizing the direct and indirect wh-questions in those reading materials. The subjects of the TG received the same reading materials as those in the NTG did. The researcher helped them understand the general meaning of those passages and analyze the sentence structures of the direct and indirect wh-questions in the reading materials. They were reminded to observe the movement of the wh-components and auxiliary verbs (including INFL) for the purpose of making them aware of the movement of those components while an English question was generated. Then the researcher provided explanations on why those components moved forwards and backwards. Therefore, the awareness to the target language phenomenon was crucial in second language acquisition, and that explained why the NTG performed differently from the TG.

Secondly, the forms of the feedbacks differentiated the accuracy of the judgment of the wh-movement of the TG. Although the L2 learners of the TG improved their accuracy in the posttest, there was still a gap to fill if they wanted to produce native-like grammaticality judgment. Some subjects were able to understand the explanation to the movement of the auxiliary verbs when their errors were pointed out, whereas some other subjects could not understand where their problems were and did not know how to grammatically move the wh-components and tense indicators when they came across wh-movement. They just depended on their so-called "sense of language" to make judgment on the grammaticality items instead of applying English wh-movement rules.

\subsubsection{A Comparison of the Pretest and Posttest within Groups}

Based on the analyzed data, the mean scores of the TG in the pretest and posttest were significantly different. Nevertheless the NTG remained a steady level. Three reasons may be illustrated as follows to explain this.

Firstly, the authentic target language input with target structure underlined triggered the subjects to notice what was intentionally required to learn from the materials. As what was supported by Krashen $(1981,1994)$ and R. Ellis (2005), the researcher of this present study agreed that enhanced L2 input took positive effect in learning an L2. R. Ellis (2005) stated that L2 input should be understandable, extensive and with large quantity. In this study, all the sentences with wh-movement in the materials that the subjects received were underlined to guide them attend the target structure. Meanwhile the researcher introduced why those sentences were underlined during every session of wh-movement instruction and provided assistance to the subjects in comprehending the sentences. The authentic target language input provided by the researcher reminded the subjects to notice the difference between English and Chinese in making wh-questions. The TG received special instructions designed according to the GARM on how to make proper wh-questions. In each section of the instruction, the researcher provided English wh-questions taken from real L2 context, so that the subjects may observe how native speakers generate questions to ask for information. The subjects were also required to take down the direct and indirect questions while they were watching English movies.

Secondly, the subjects of the TG became aware of the fronting of the questioned part and the auxiliary verbs or INFL while raising a wh-question to ask for information. As suggested by R. Ellis (2005), the researcher extended the assignment in this research requiring the subjects to find out more wh-questions on their own from those English reading materials that they could get access to. And they needed to make their own sentences 
following the extracted English questions. For example, a student searched in a journal in English and took out a direct wh-question as follows,

4a. How could you ignore such a big error?

And then he made his own wh-question following the structure of above one as,

4b. How would Mr. Smith solve this problem?

4c. How did Michael send this package to his girlfriend?

The subjects also took out an indirect wh-question as follows,

5a. You must tell me where she is.

And then he made his own wh-question following the structure as,

5b. Zeke has pointed out where the problem is.

5c. Chad didn't explain why he was late for class.

The purpose of assigning so was to encourage the subjects to enlarge the input with wh-movement and then to comprehend. By requiring such exercise, the researcher intended to raise the subjects' awareness of the target structure and then further understood how to make wh-question and move the auxiliary verb or INFL in the wh-question.

Thirdly, the researcher provided corrective feedbacks to the subjects of the TG, which may help them correct the errors in their homework. During the experiment after every lecture on the wh-movement, the subjects of the TG extracted wh-questions, both direct and indirect, from natural language contexts and made their own wh-questions following the structure. The researcher read through all their sentences and provided written corrective feedbacks to them for the purpose of observing to what extent they understood and applied the rules. At the same time, the subjects of the NTG did not receive corrective feedbacks on their performance in making wh-movement. For example one of the subjects handed in his assignment like this,

6a. Extract: Part of me wanted to confront him and demand to know what his problem was.

6b. Subject's work: *My mother want to congratulate me and encouraged to find out what is the truth.

The researcher provided comments on this indirect sentence by writing,

The verb "want" should be past tense. The clause "what is the truth" was embedded in a main clause. So it should be an indirect question. Firstly the verb "is" should be changed into past tense to make the whole sentence coordinate in tense. Secondly it should be returned to its original place as in the statement "the truth was ...”

In summary, the TG performed better in the posttest because they received wh-movement focused L2 input, they were reminded to become aware of the rules of fronting the wh-components, the moving of the auxiliary verb or INFL back and forth and they received corrective feedbacks.

\subsection{Research Question 2}

In response to research question two, "What are the grammatical errors made by L2 English learners concerning wh-movement before and after GARM based explanations on wh-movement?” the grammar errors made by the participants were coded, counted and discussed.

\subsubsection{Frequency of Errors in Pretest}

Based on the data reported previously, the most frequently appeared two errors were Error 3, no movement forward and Error 4, no movement backward ones in the pretest for the TG.

As for the Error 3, no movement forward error, the subjects either judged the grammatical ones as ungrammatical as 7a below, and fronted the auxiliary verb; or judged the ungrammatical ones as grammatical as $7 \mathrm{~b}$ below.

7a. On what day will they leave for Shanghai?

7b. *Why Africa is so poor?

3 out of 40 from the TG and 2 out of 40 from the NTG judged 7a as ungrammatical but left it with no correction. 13 out of 40 from the TG and 15 out of 40 from the NTG judged it ungrammatical and corrected this question into the following wh-question as $7 \mathrm{~b}$.

Both the TG and the NTG had 26 out of 40 subjects who judged the direct wh-question as 8a below as 
grammatical and therefore did not make any corrections to it though it was judged ungrammatical by the native speakers and made corrections to it as $8 \mathrm{~b}$.

8a. *To whom John gave a glass of water.

8b. To whom did John give a glass of water.

The reason of such no movement forward was that the subjects' L1 parameters, which required no tense indicator moving, prevented them from fronting it. The English subject-verb-object wording order was same to that of the Chinese. So the subjects just made judgment by reading the sentences and felt comfortable to judge questions like 8a with unfronted tense indicator as grammatical. This explanation may be supported by the interview data as one of the subjects reported,

Researcher: How did you judge that this question was right?

Subject: I just read it. And this sentence looks ok.

Researcher: Did you notice that when you ask a question, the verb "gave" should be split into "give and -ed", and the tense indicator "-ed" should be moved to the front of the sentence after the wh-word"

Subject: Oh, sorry. I didn’t notice that. I should have done that but I forgot.

As for the Error 4, no movement backward errors, when the subjects were taking the pretest, both the TG and the NTG made errors in judging the grammaticality of the indirect wh-questions. They seemed to have no problems with the positions of the wh-components but problematic in judging the positions of the auxiliary verbs or the tense indicator in the indirect questions. Take the following 9a extracted from the pretest as an example.

9a. "The tiger searched everywhere in order to find out where had the rabbit gone.

9a is a statement with an embedded wh-question, which is termed indirect wh-question in this present research. 16 out of 40 subjects from the TG and 18 out of 40 subjects from the NTG believed it was grammatical and made no corrections to it, though it was judged ungrammatical by the native speakers. And the corrected version of $9 \mathrm{a}$ is $9 \mathrm{~b}$ as follows.

9b. The tiger searched everywhere in order to find out where the rabbit had gone.

Such auxiliary verb misplaced error was related to unsuccessfully reset L2 parameters. Those who judged 9a as grammatical had reset their L1 Chinese wh-in-situ parameter to L2 wh-component fronted parameter. However, the L2 parameter was partially reset because the auxiliary verb's position was mistakenly judged, as English requires the auxiliary verb moves back in the relative clause while making indirect wh-questions. The L2 learners knew the rules of fronting wh-word and auxiliary verb to make wh-questions. But when the wh-questions were embedded in a main clause, they forgot to return the auxiliary verb to its original place so that their indirect wh-questions appeared with direct question characteristics. Before the subjects took this present research they had learned English for six years starting from the first year of middle school. They were able to front the wh-word to the beginning of a question because that was overtly different from their L1 and therefore their L2 teachers emphasized the fronting over and over. However, things were different in making indirect questions. The L2 teachers helped the L2 learners understand the structures of the embedded clause, which was another point overtly different from Chinese. But the places of English auxiliary verb or INFL were less frequently corrected by the teachers. Consequently, the L2 learners received less training on returning the auxiliary verbs to its original place while making indirect questions. This gives more evidence to support the importance of language awareness in L2 learning.

The researcher interviewed a subject and the interview data suggested that the subject made such mistake as no auxiliary verb moving backwards because the corrective feedback that she received was not enough to call on her awareness of the movement of the auxiliary verb.

\subsubsection{Frequency of Errors in Posttest}

According to the data presented previously, the number of the Error 3, namely the no movement forward, made by the TG were less than that of the NTG. Generally speaking, the TG made all together 159 Error 3 whilst the NTG made 220 ones. In other words, after receiving the instruction on the wh-movement rules, the subjects of the TG were able to lessen their errors in moving forward the wh-components and the auxiliary verbs or INFL though there were still some problems.

Previously, the subjects had difficulties in moving the auxiliary verbs or INFL in questions with complex wh-component. Take item 1 in the post GJT as an example repeated as 10a below.

10a. "What the hell you two have done to that poor dog? 
22 out of 40 from the TG and 32 out of 40 from the NTG judged this question as grammatical and left it without any correction. On the contrary, the native speakers judged this wh-question as ungrammatical and corrected as 10b below.

10b. What the hell have you two done to that poor dog?

Another example of such error was item 26 repeated as 11a below.

11a. "How soon he is about to become the king?

6 out of 40 from the TG and 18 out of 40 from the NTG judged this question as grammatical whereas it was judged as ungrammatical by the native speakers and corrected it as $11 \mathrm{~b}$ below.

11b. How soon is he about to become the king?

The reason that the subjects failed to make proper judgment on these ungrammatical wh-question was that they were interfered with by the complex wh-components, "what the hell" as in 10a and "how soon" as in 11a. They had difficulties in placing the auxiliary verbs. In other words, though they were able to move the auxiliary verbs or INFLs to be after wh-word in direct wh-questions, they were confused about where to put the auxiliary verbs when the wh-component had more than one word. This phenomenon indicated that the L2 parameters may not be fully reset by the L2 learners when they were learning the second language.

From above data, it could be concluded that after the subjects of the TG received the instructions on the movement of the wh-components and the auxiliary verbs or INFL, the subjects may have some L2 parameters unsuccessfully reset though the mean scores of the TG was significantly higher than that of the NTG.

As for the fourth type of error, i.e. no movement backward, the frequency of this type of error made by the TG was significantly reduced compared to that of the NTG. Generally speaking, the fourth type of error appeared 106 times in the post GJT done by the TG, whereas 252 times in the post GJT done by the NTG. In other words, the TG significantly improved the accuracy in judging the grammaticality of the wh-movement, as well as the movement of the auxiliary verbs or INFLs.

\section{Conclusion}

In this current study, the effect of the grammar awareness-raising model took positive effect in facilitating the L2 learners moving the wh-components and auxiliary verbs (including tense indicators). For the purpose of testifying the hypothesis, an experiment consisting of pretest-treatment-posttest was designed by using the GJT as the data collection instrument. The pedagogical intervention, namely the instruction on wh-movement, in this study aimed at improving the subjects' performance in judging the grammaticality of both the direct and indirect wh-questions.

In order to answer the two research questions, the mean scores of the participants in the pretest were compared and analyzed. By comparing the mean scores, it was reported that the subjects of the TG had similar performance with those of the NTG. Both groups performed significantly different from the native speakers. After the instructions on the wh-movement, the subjects were required to take the posttest of the GJT. The mean scores of the TG and NTG exhibited statistically meaningful differences, which may indicate the effectiveness of the instructions designed according to the grammar awareness-raising model. These findings could support positively to the Research Hypothesis, that is, L2 learners could improve their accuracy of wh-questions with the help of GARM.

The frequencies of each type of errors in the pretest and posttest were compared. The most frequently appeared errors were the no movement forward error and no movement backward error. The reasons to explain this phenomenon was that the L2 learners were under the influence of their L1, and therefore made English wh-questions with Chinese characteristics. It was reported that the frequencies of these two types of errors of the TG were lessened after the pedagogical intervention.

It is concluded that by raising the awareness of the target linguistic structure, the language learners may improve their accuracy in making wh-movement as well as the auxiliary verbs, including INFL.

\section{Acknowledgements}

My greatest appreciation would go to my supervisor Dr. Sanooch Segkhoontod Na-Thalang whose kindness helped and encouraged me in writing my Ph. D. dissertation. I am also grateful to all the participants who took part in my research. I would also like to extend my appreciation to my baby and the whole family for their encouragement and support. I personally take the responsibility of any mistake in this paper. 


\section{References}

Al-Hejin, B. (2005). Attention and awareness: Evidence from cognitive and second language acquisition research. Teachers College, Columbia University Working Papers in TESOL \& Applied Linguistics, 4(1).

Alanen, R. (1995). Input enhancement and rule presentation in second language acquisition. In R. Schmidt (Ed.), Attention and awareness in foreign language learning (pp. 259-302). Hawai'i: University of Hawai'i Press.

Allport, A. (1988). What concept of consciousness? In A. J. Marcel, \& E. Bisiach (Eds.), Consciousness in Contemporary Science (pp. 159-182). London: Clarendon Press. http://dx.doi.org/10.1093/acprof:oso/9780198522379.003.0007

Bley, Vroman R., \& Yoshinaga, N. (2000). The acquisition of multiple wh-questions by high-proficiency non-native speakers of English. Second Language Research, 16(1), 3-26. http://dx.doi.org/10.1191/026765800676857467

Choi, Y. S. (2007). Intervention effect in Korean wh-questions: Indefinite and beyond. Lingua, 117(12), 2055-2076. http://dx.doi.org/10.1016/j.lingua.2007.01.001

Chomsky, N. (1975). Reflections on Language. New York: Pantheon.

Chomsky, N. (1986). Knowledge of Language: Its nature, origin, and use. Westport: Praeger Publishers.

Ellis, N. C. (2002). Reflections on frequency effects in language processing. Studies in second language acquisition, 24(2), 297-339. http://dx.doi.org/10.1017/S0272263102002140

Ellis, R. (2005). Principles of instructed language learning. System, 33(2), 209-224. http://dx.doi.org/10.1016/j.system.2004.12.006

Hawkins, R., \& Hattori, H. (2006). Interpretation of English multiple wh-questions by Japanese speakers: A missing uninterpretable feature account. Second Language Research, 22(3), 269-301. http://dx.doi.org/10.1191/0267658306sr269oa

Kennedy, S. (2012). Exploring the relationship between language awareness and second language use. TESOL Quarterly, 46(2), 398-408. http://dx.doi.org/10.1002/tesq.24

Krashen, S. (1981). Second language acquisition and second language learning. Oxford: Pergamon.

Krashen, S. (1994). The input hypothesis and its rivals. In N. Ellis (Ed.), Implicit and Explicit Learning of Languages (pp. 45-77). London: Academie Press.

Li, X. (1998). Adult L2 accessibility to UG: An issue revisited. In S. Flynn, G. Martohardjono, \& W. A. O'Neil (Eds.), The generative study of second language acquisition (pp. 89-110). New Jersey: Lawrence Erlbaum Associates Inc.

Nazari, N. (2013). The effect of implicit and explicit grammar instruction on learners' achievements in receptive and productive modes. Procedia -Social and Behavioral Sciences, 70(0), 156-162. http://dx.doi.org/10.1016/j.sbspro.2013.01.051

Park, H. (2000). Child second language acquisition and grammatical theories: The minimalist program and optimality theory. Ph. D. Dissertation, The University of Arizona. Retrieved from http://hdl.handle.net/10150/252897 (9972107)

Reber, A. S. (1989). Implicit learning and tacit knowledge. Journal of Experimental Psychology: General, 118, 219-235.

Rezaei, A. A., \& Hosseinpur, R. M. (2011). On the role of consciousness-raising tasks in learning grammar. The Iranian EFL Journal, 39(3), 237.

Schmidt, R. (1990). The role of consciousness in second language learning. Applied Linguistics, 11(2), 129-158.

Schmidt, R. (2012). Attention, awareness, and individual differences in language learning. Perspectives on Individual Characteristics and Foreign Language Education, 6, 27. http://dx.doi.org/10.1515/9781614510932.27

Shahrour, G., \& Bull, S. (2008). Does 'notice' prompt noticing? Raising awareness in language learning with an open learner model. In W. Nejdl, J. Kay, P. Pu., \& E. Herder (Eds.), Adaptive Hypermedia and Adaptive Web-Based Systems (Vol. 5149, pp. 173-182). Springer Berlin Heidelberg. http://dx.doi.org/10.1007/978-3-540-70987-9_20

Slavkov, N. (2009). The acquisition of complex wh-questions in the L2 English of Canadian French and 
Bulgarian speakers: Medial wh-constructions, inversion phenomena, and avoidance strategies. Ph. D., University of Ottawa. Retrieved from http://aix1.uottawa.ca/ nslav061/SlavkovThesis2009WebVersion.pdf

Svalberg, A. M. L. (2007). Language awareness and language learning. Language Teaching, 40(04), 287-308. http://dx.doi.org/10.1017/S0261444807004491

Tayyebi, G. (2012). The availability of universal grammar to second language learners: A case of wh-movement. International Journal of English Linguistics, 2(3), 34. http://dx.doi.org/10.5539/ijel.v2n3p34

Tsimpli, I. M., \& Dimitrakopoulou, M. (2007). The interpretability hypothesis: evidence from wh-interrogatives in second language acquisition. Second Language Research, 23(2), 215-242. http://dx.doi.org/10.1177/0267658307076546

White, L., \& Juffs, A. (1998). Constraints on wh-movement in two different contexts of nonnative language acquisition: Competence and processing. In S. Flynn, G. Martohardjono, \& W. A. O'Neil (Eds.), The Generative Study of Second Language Acquisition (pp. 111-129). New Jersey: Lawrence Erlbaum Associates, Inc.

\section{Notes}

Note 1. Ungrammatical sentences in this paper are marked with an asterisk $(*)$.

Note 2. The correction marks $\sqrt{ }$ or $X$ in the parenthesis were what the subjects marked on the test paper.

\section{Copyrights}

Copyright for this article is retained by the author(s), with first publication rights granted to the journal.

This is an open-access article distributed under the terms and conditions of the Creative Commons Attribution license (http://creativecommons.org/licenses/by/3.0/). 